\title{
Aged Garlic Extract Reduces ROS Production and Cell Death Induced by 6-Hydroxydopamine through Activation of the Nrf2-ARE Pathway in SH-SY5Y Cells
}

\author{
Kohfuku Kohda*, Hitomi Goda, Kei Itoh, Keijiro Samejima, Tomoko Fukuuchi \\ Graduate School of Pharmaceutical Sciences, Musashino University, Tokyo, Japan. \\ Email: ${ }^{*}$ kohda@musashino-u.ac.jp
}

Received September $29^{\text {th }}, 2012$; revised November $7^{\text {th }}, 2012$; accepted December $12^{\text {th }}, 2012$

\begin{abstract}
Many degenerative or pathological processes, such as aging, cancer and coronary heart disease, are related to reactive oxygen species (ROS) and radical-mediated reactions. We examined the effectiveness of aged garlic extract (AGE), a garlic preparation rich in water-soluble cysteinyl moieties, for protection of cells from ROS produced by 6-hydroxydopamine (6-OHDA) using human neuroblastoma SH-SY5Y cells. Concomitant treatment of cells with AGE (2 and 4 $\mathrm{mg} / \mathrm{ml}$ ) showed the dose-dependent protective effect on the cell death induced by 6-OHDA. In addition, the AGE treatment significantly suppressed the increase of ROS generation by 6-OHDA. Furthermore, the protective effect of AGE was accompanied by activation of the nuclear factor erythroid 2-related factor 2 (Nrf2)-antioxidant response element (ARE) pathway and the increase of mRNAs of heme oxygenase-1 and NAD(P)H quinone oxidoreductase 1. These two enzymes are important in the cellular antioxidant system. These results indicated that AGE protected cells from ROS damage by not only capturing ROS directly but also activating the cellular antioxidant system by stimulating antioxidant gene expression via the Nrf2-ARE pathway. The present study suggested that AGE may be useful for prevention and treatment of cell damage caused by ROS.
\end{abstract}

Keywords: Aged Garlic Extract (AGE); 6-OHDA; ROS; Nrf2-ARE Pathway; SH-SY5Y Cells

\section{Introduction}

Garlic (Allium sativum L.) has been used for the prevention and treatment of a variety of diseases including heart disease and cancer [1]. Among the various garlic preparations available, aged garlic extract (AGE) preparation employs a unique manufacturing process, involving mild and long extraction up to 20 months that leads to enrichment of water-soluble cysteinyl moieties and reduction of harsh agents and the garlic odor [2]. AGE is also less irritating and has little toxic side effects compared to the raw garlic [3]. AGE and its components have been shown to possess pharmacologically beneficial activities, such as anti-stress [4], anti-fatigue [5], immunomodulatory activities [6] as well as cardiovasculo- [7-9] and hepato-protective properties [10]. Moreover, AGE has been shown to possess superior antioxidant properties compared to the raw garlic, which may be important for its pharmacological effects [11]. In our previous study we have demonstrated that AGE enhances neurite outgrowth of PC12 cells by its scavenging effect on reactive

*Corresponding author. oxygen species (ROS) [12].

Although oxygen is essential to many living organism for the production of energy to fuel biological processes, oxygen-centered free radicals and other ROS produced excessively can cause cell damage and death. The human body has both enzymatic and non-enzymatic antioxidant systems to protect cellular molecules against ROS-induced damage [13]. However, these innate defenses may not be sufficient if oxidative stress is severe or continuous. There is an increasing body of evidence suggesting that many degenerative or pathological processes, such as aging, cancer and coronary heart disease, are related to ROS and radical-mediated reactions [14,15]. Antioxidant agents can reduce oxidative damage to cells, defend against cancer-causing agents and help lower the risk of cardiovascular disease, diabetes and some forms of dementia including Alzheimer's disease [16,17]. In our series of survey to find active compounds that stimulate nerve cells, we have shown that fullerene derivatives produce the enhancing effect on neurite outgrowth by scavenging cytotoxic ROS [18]. Recently Baati et al. have reported that the repeated oral administration of fullerene extends the lifespan of rats by attenuation of the 
oxidative stress [19].

6-Hydroxydopamine (6-OHDA) is one of potent neurotoxins and induces cell death associated with ROS generation [20]. It has been reported that treatment with 6-OHDA causes the activation of c-JUN N-terminal kinase and caspases, DNA fragmentation and apoptosis in various cell types [21-23].

Nuclear factor erythroid 2-related factor 2 (Nrf2) is a basic leucine zipper transcription factor, and forms heterodimers with the small Maf proteins and binds to the antioxidant response element (ARE). Nrf2 plays a critical role in the constitutive and inducible expression of numerous detoxifying and antioxidant genes, including heme oxygenase-1 (HO-1) and $\mathrm{NAD}(\mathrm{P}) \mathrm{H}$ quinone oxidoreductase 1 (NQO1), through activation of the ARE in the regulatory region of the gene [24-27]. Nrf2 binds to Keap1, a cytoplasmic cysteine riched protein, under normal conditions. But when cells undergo certain adverse conditions such as oxidative stress, Nrf2 is liberated from Keap1, and allowed to translocate into the nucleus and bind to ARE $[28,29]$. Therefore, the Nrf2-Keap1 complex is thought to be a cytoplasmic sensor system for oxidative stress.

In the present study, we examined the protective effect of AGE on the cell death induced by 6-OHDA and its ability to activate antioxidant systems in cultured SHSY5Y cells. Our results indicated that AGE effectively inhibited the cell death induced by ROS through capturing ROS directly and also inducting antioxidant gene expression via the Nrf2-ARE pathway. Therefore AGE may be useful for the prevention and treatment of diseases associated with ROS.

\section{Materials and Methods}

\subsection{Materials}

6-OHDA, phenylmethylsulfonyl fluoride, leupeptin, DMEM (low glucose) with L-glutamine and Ham's F-12 with L-glutamine were purchased from Wako Pure Chemical Ind., Ltd. (Osaka, Japan). Fetal bovine serum (FBS) was obtained from Nichirei Biosciences (Tokyo, Japan). Trypsin-EDTA was purchased from Gibco Invitrogen (Carlsbad, CA, USA). 2',7'-Dichlorodihydrofluorescin diacetate (DCFH-DA), 3-(4,5-dimethylthiazol-2-yl)-2,5diphenyltetrazolium bromide (MTT), $N$-methyl-4-phenylpyridinium ion $\left(\mathrm{MPP}^{+}\right)$, tert-butylhydroquinone (tBHQ) and primers for HO-1, NQO1, Nrf2 and glyceraldehyde-3-phosphate dehydrogenase (GAPDH) were obtained from Sigma-Aldrich (St. Louis, MO, USA). RNAiso and PrimeScript RT reagent kit were purchased from Takara Bio Inc. (Shiga, Japan). Anti-Nrf2 antibody was purchased from Santa Cruz Biotechnology (Santa Cruz, CA, USA). Anti-Lamin B1 antibody was obtained from
Abcam (Tokyo, Japan). 1-(4-Amino-2-methyl-5-pyrimidinyl)methyl-3-(2-chloroethyl)-3-nitrosourea hydrochloride (ACNU or nimustine hydrochloride) was a gift from Daiich Sankyo Co., Ltd. (Tokyo, Japan).

\subsection{Preparation of AGE}

AGE was prepared as reported [12] and supplied by Wakunaga Pharmaceutical Co. Ltd. (Hiroshima, Japan). Briefly, garlic cloves (Allium sativum L.) grown under controlled organic conditions without the use of chemical fertilizers, herbicides or pesticides were sliced and soaked in an aqueous ethanol solution and extracted/aged up to 20 months at room temperature. AGE was obtained by removing ethanol from the AGE extract under in vacuo.

\subsection{Cell Culture and Treatment}

The human neuroblastoma SH-SY5Y cells were purchased from ATCC (Manassas, VA, USA). SH-SY5Y cells were cultured in DMEM/F-12 medium supplemented with $10 \%$ FBS, penicillin $(100 \mathrm{U} / \mathrm{ml}) /$ streptomycin $(100$ $\mu \mathrm{g} / \mathrm{ml})$ in a humidified $5 \% \mathrm{CO}_{2}$ atmosphere at $37^{\circ} \mathrm{C}$. In general, cells were seeded on a 96-well multi-dish $(2.5 \times$ $10^{4}$ cells/well) and incubated for $24 \mathrm{~h}$ before use. The cytotoxicity of 6-OHDA, $\mathrm{MPP}^{+}$and ACNU was assessed by treating cells for $24 \mathrm{~h}, 72 \mathrm{~h}$ and $48 \mathrm{~h}$, respectively.

\subsection{Cell Viability}

MTT assay [30] was used to determine the cell viability. Briefly, after the medium was replaced with the one containing MTT $(0.25 \mathrm{mg} / \mathrm{ml})$, the cell culture was continued for $5 \mathrm{~h}$. After the medium containing MTT was removed and a $10 \%$ sodium dodecyl sulfate (SDS) solution in $\mathrm{H}_{2} \mathrm{O} / \mathrm{DMF}=1 / 1(\mathrm{v} / \mathrm{v})$ was added, the culture dishes were then left standing overnight at room temperature. Optical absorption was measured at $550 \mathrm{~nm}$. Cell viability was expressed as $\%$ of the control.

\subsection{Measurement of ROS Generation}

ROS generation was measured according to the method of Keston et al. [31] using the 24-well multi-dishes. Briefly, DCFH-DA $(100 \mu \mathrm{M})$ dissolved in $500 \mu \mathrm{l}$ of the medium without serum (ns-medium) was added to cell culture $\left(2.6 \times 10^{5}\right.$ cells/well $)$ and cells were incubated for $60 \mathrm{~min}$. After cells were washed twice with ns-medium, the fresh ns-medium with or without AGE was added. After 30 min incubation, 6-OHDA was added and cells were cultured for $1 \mathrm{~h}$. An equal volume of RIPA buffer (includes $100 \mathrm{mM}$ Tris- $\mathrm{HCl}$ (pH 8.0), $300 \mathrm{mM} \mathrm{NaCl}, 1 \%$ sodium deoxycholate, $0.2 \%$ SDS and $2 \%$ Triton X-100) was added and the fluorescence was measured (excitation at $490 \mathrm{~nm}$ and emission at $530 \mathrm{~nm}$ ). In order to avoid the 
elevation of the background in the assay system in which a light-sensitive DCFH-DA was used, these experiments were performed in dark place.

\subsection{Expression of mRNAs of HO-1, NQO1 and Nrf2}

After cells were treated with AGE $(4 \mathrm{mg} / \mathrm{ml})$ for $24 \mathrm{~h}$, total RNA was extracted with RNAiso. cDNA was synthesized using the PrimeScript RT reagent kit. The realtime PCR using SYBR Green detection system was performed on an Applied Biosystems 7500 real-time PCR system (Applied Biosystems Japan Ltd.). Relative mRNA levels were quantified using the comparative CT method with Applied Biosystems 7500 System Software. The mRNA values were normalized against the average values of GAPDH. The primers used for real-time PCR were as follows; 5'-AGAGCTGCACCGCAAGGCTG-3' (forward) and 5'-ACCAGCAGCTCGGGCTCTGT-3' (reverse) for HO-1, 5'-ATGTATGACAAAGGACCCTTCC-3' (forward) and 5'-TCCCTTGCAGAGAGTACATGG-3' (reverse) for NQO1, 5'-ACACGGTCCACAGCTCATC-3' (forward) and 5'-TGTCAATCAAATCCATGTCCTG-3'(reverse) for Nrf2, 5'-GCCTTCCGTGTCCCCACTGC-3' (forward) and 5'-CAATGCCAGCCCCAGCGTCA-3' (reverse) for GAPDH.

\subsection{Preparation of Nuclear Extract}

SH-SY5Y cells were treated with tBHQ $(50 \mu \mathrm{M})$ for 3.5 $\mathrm{h}$ or with AGE $(4 \mathrm{mg} / \mathrm{ml})$ for 1,3 or $6 \mathrm{~h}$ in $100-\mathrm{mm}$ dishes. Nuclear extracts were prepared using the method of Hara et al. with slight modifications [32]. Briefly, treated cells were washed once with ice-cold phosphatebuffered saline, and scraped off in a buffer A (including $20 \mathrm{mM}$ HEPES ( $\mathrm{pH} 7.8$ ), $15 \mathrm{mM} \mathrm{KCl}, 2 \mathrm{mM} \mathrm{MgCl} 2,1$ $\mathrm{mM}$ DTT, $0.5 \mathrm{mM}$ phenylmethylsulfonyl fluoride and 10 $\mu \mathrm{g} / \mathrm{ml}$ leupeptin). The cell suspension was allowed to stand for $15 \mathrm{~min}$, and then cells were lysed for $5 \mathrm{~min}$ after addition of $0.2 \%$ Nonidet P-40. The cell lysates were centrifuged for $5 \mathrm{~min}$ at $800 \mathrm{~g}$, and the pellets were resuspended in buffer B (including $20 \mathrm{mM}$ HEPES $(\mathrm{pH}$ 7.8), $0.4 \mathrm{M} \mathrm{NaCl}, 2 \mathrm{mM} \mathrm{MgCl}, 1 \mathrm{mM}$ DTT, $0.5 \mathrm{mM}$ phenylmethylsulfonyl fluoride, $10 \mu \mathrm{g} / \mathrm{ml}$ leupeptin and $25 \%$ glycerol), followed by the gentle shaking for $30 \mathrm{~min}$. After the suspension was centrifuged for $20 \mathrm{~min}$ at $20,000 \mathrm{~g}$, the supernatant was stored at $-80^{\circ} \mathrm{C}$. All procedures were performed at $4^{\circ} \mathrm{C}$. Protein concentrations in nuclear extracts were determined using a modified Bradford method [33].

\subsection{Western Blotting}

Nuclear protein extracts $(10 \mu \mathrm{g}$ protein/each sample) were electrophoresed in a 7.5\% SDS-polyacrylamide gel, and then the protein bands were transferred onto a PVDF membrane. The membrane was incubated with anti-Nrf2 antibody (1:200) or anti-Lamin B1 antibody (1:1000), followed by incubation with horseradish peroxidaseconjugated secondary antibody (1:1000). Proteins were visualized using the ECL plus western blotting detection system (GE Healthcare Japan).

\subsection{Statistical Analysis}

The data are expressed as the mean \pm S.D. Statistically significant differences were determined using Student's $t$-test or one-way ANOVA followed by Bonferroni's multiple comparison test. Differences at $p<0.05$ were considered to be significant.

\section{Results}

\subsection{Concomitant Treatment of AGE Suppressed the Cell Death Induced by 6-OHDA}

Three test compounds, 6-OHDA, $\mathrm{MPP}^{+}$and $\mathrm{ACNU}$, that induce cytotoxicity in nerve cells were chosen and the protective effect of AGE ( 2 and $4 \mathrm{mg} / \mathrm{ml}$ ) on cell death induced by these compounds was examined. 6-OHDA is a potent neurotoxin and induces cell death associated with ROS generation [20], whereas $\mathrm{MPP}^{+}$is an inducer of Parkinsonism and inhibitor of mitochondrial respiration chain [34] and ACNU is an alkylating anticancer drug used for the therapy of brain cancer [35]. The cytotoxicity of each compound in SH-SY5Y cells was examined and the dose-response curve of each compound was obtained. As shown in Figure 1, 6-OHDA caused 50\% cell death at a concentration, $105 \mu \mathrm{M}$ as previously reported [20]. The results in Figure 2 showed that the concomitant treatment of cells with 2 or $4 \mathrm{mg} / \mathrm{ml}$ of AGE significantly reduced the extent of cell death induced by 100 or $150 \mu \mathrm{M}$ of 6-OHDA, respectively. We next examined whether AGE inhibited the cell death induced by $\mathrm{MPP}^{+}$and ACNU. As shown in Figures and 4, respectively, AGE gave no protective effect on cell death caused by $\mathrm{MPP}^{+}$and ACNU. These results indicated that among three test compounds examined, the protective effect of AGE on cell death was only observed in the case of 6-OHDA that produced ROS.

\subsection{AGE Suppressed ROS Generation Induced by 6-OHDA}

In order to determine whether AGE suppressed ROS generation induced by 6-OHDA, we examined the intracellular level of ROS using a redox-sensitive fluorescence reagent, DCFH-DA [31]. As shown in Figure 5, addition of 6-OHDA at 100 and $200 \mu \mathrm{M}$ increased ROS production in SH-SY5Y cells, whereas concomitant treat- 


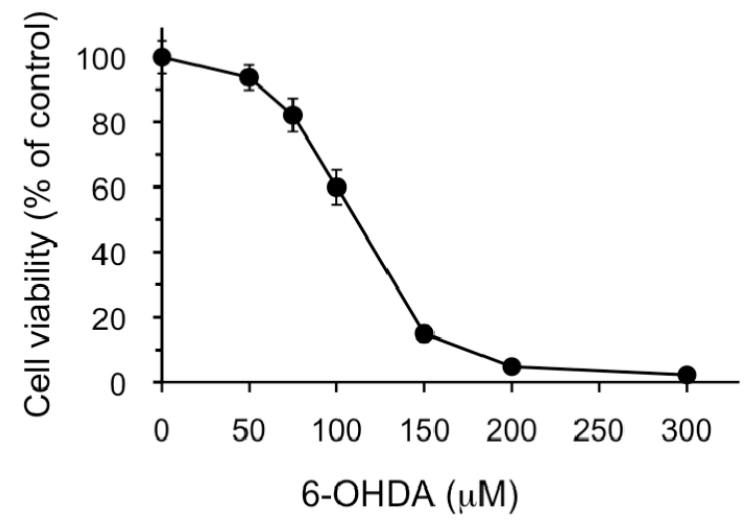

Figure 1. Cytotoxicity of 6-OHDA against SH-SY5Y cells. SH-SY5Y cells were exposed to the indicated concentrations of 6-OHDA for $24 \mathrm{~h}$. Cell viability was assessed using MTT assay as described in the Materials and Methods. The data are expressed as mean \pm S.D. $(n=6)$.



Figure 2. Effect of AGE on 6-OHDA-induced cytotoxicity. SH-SY5Y cells were treated with AGE ( 2 or $4 \mathrm{mg} / \mathrm{ml}$ ) for 30 min, and then the cells were exposed to 6-OHDA (100 or $150 \mu \mathrm{M})$ for $24 \mathrm{~h}$. Cell viability was assessed using MTT assay as described in the Materials and Methods. The data are expressed as mean \pm S.D. $(n=5-6)$. *** Denotes a significant difference compared with the corresponding value of the system without AGE $(p<0.01)$ as evaluated by Bonferroni's multiple comparison test after one-way ANOVA.

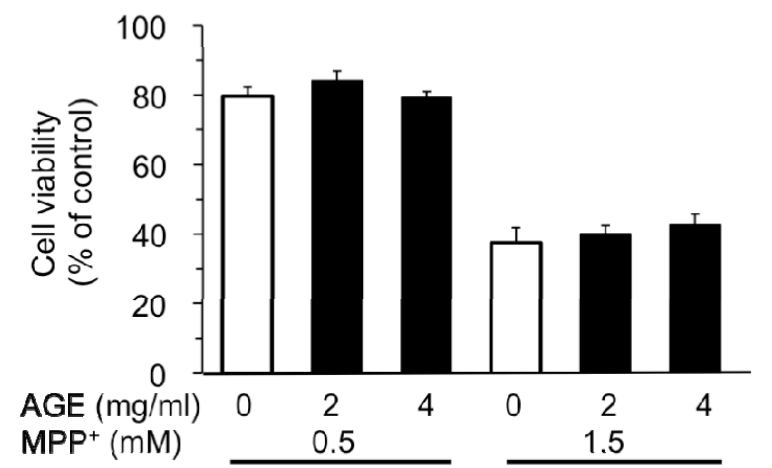

Figure 3. Effect of AGE on $\mathrm{MPP}^{+}$-induced cytotoxicity. The experimental procedures are the same as described in Figure 2 legend except that the exposure time to $\mathrm{MPP}^{+}$was $72 \mathrm{~h}$. The data are expressed as mean \pm S.D. $(n=6)$.



Figure 4. Effect of AGE on ACNU-induced cytotoxicity. The experimental procedures are the same as described in Figure 2 legend except that the exposure time to ACNU was $48 \mathrm{~h}$. The data are expressed as mean \pm S.D. $(n=6)$.

ment of cells with AGE $(4 \mathrm{mg} / \mathrm{ml})$ significantly suppressed the increase of ROS. In addition, AGE itself caused a small but significant increase of ROS.

\subsection{AGE Increased the Expression of mRNAs of HO-1 and NQO1}

With regard to the mode of protective action of AGE, two possibilities could be considered; 1) AGE itself captured and thus lowered ROS as already being reported $[11,36,37]$ and/or 2) AGE activated the antioxidant response system in cells that can reduce the ROS level. As the representative antioxidant proteins, HO-1 and NQO1 were chosen and the effect of AGE on the level of their mRNAs was examined using real-time PCR. As shown in Figure 6, AGE significantly increased the level of mRNAs of HO-1 and NQO1.

\subsection{AGE Induced the Nuclear Translocation of Nrf2}

Nrf2 controls the expression of a cluster of antioxidant genes by binding to ARE that exists in the upstream of antioxidant genes [24-27,38]. Thus we examined the possibility that AGE activated the Nrf2-ARE pathway and the ARE-driven gene expression [39]. In this experiment, the effect of AGE $(4 \mathrm{mg} / \mathrm{ml})$ was examined during 1, 3 and $6 \mathrm{~h}$ treatment and tBHQ was used as a positive control to activate the Nrf2-ARE pathway [29,40]. As shown in Figure 7, AGE treatment induced the nuclear translocation of Nrf2 as early as $1 \mathrm{~h}$ and its effect persisted at 6 $\mathrm{h}$. These findings suggested that AGE stimulated the expression of gene encoding HO-1 and NQO1 via the Nrf2-ARE pathway. The level of Nrf2 mRNA, however, was not increased by AGE (data not shown).

\subsection{Pre-Treatment of AGE Suppressed the Cell Death Induced by 6-OHDA}

Based on the above findings that AGE activated the cel- 


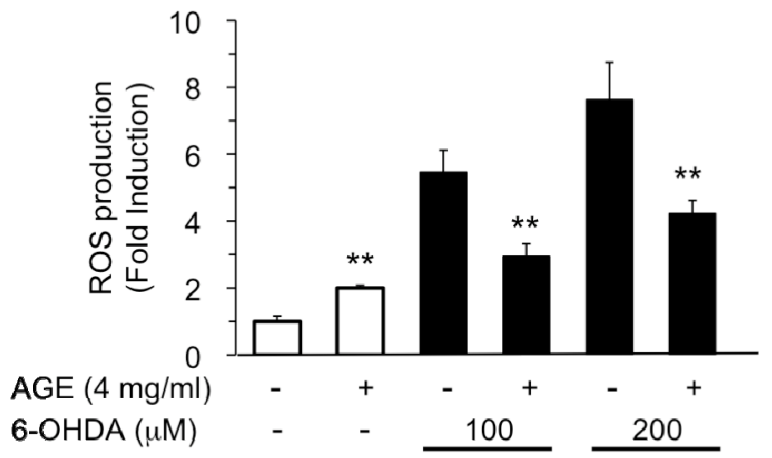

Figure 5. Inhibition of 6-OHDA-induced ROS production by AGE. SH-SY5Y cells were treated with AGE $(4 \mathrm{mg} / \mathrm{ml})$ for $30 \mathrm{~min}$, and then the cells were further exposed to 6-OHDA (100 or $200 \mu \mathrm{M})$ for $1 \mathrm{~h}$. ROS production was assayed as described in the Materials and Methods. The data are expressed as mean \pm S.D. $(n=4)$. *** Denotes a significant difference compared with the corresponding value of the system without AGE $(p<0.01)$ as evaluated by $t$-test.

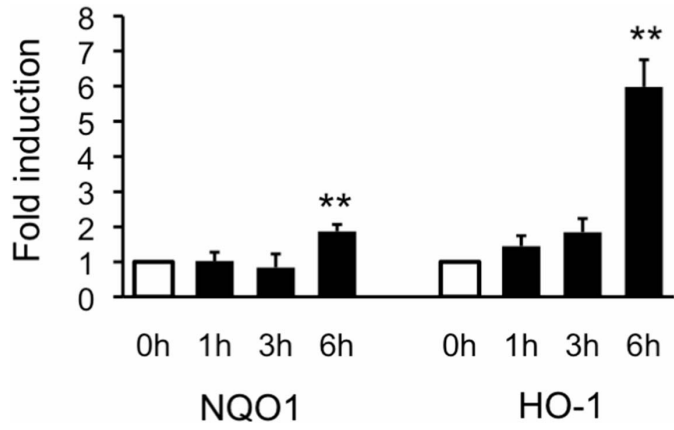

Figure 6. Induction of mRNAs of HO-1 and NQO1 by AGE. SH-SY5Y cells were treated with AGE (4 mg/ml) for 1,3 or $6 \mathrm{~h}$. Total RNA was prepared, and then RT-PCR was performed as described in the Materials and Methods. The data are expressed as fold induction relative to the level at 0 h. $(\mathbf{n}=3)$. ${ }^{* * *}$ Denotes a significant difference compared with the $0 \mathrm{~h}$ value $(p<0.01)$ as evaluated by Bonferroni's multiple comparison test after one-way ANOVA.

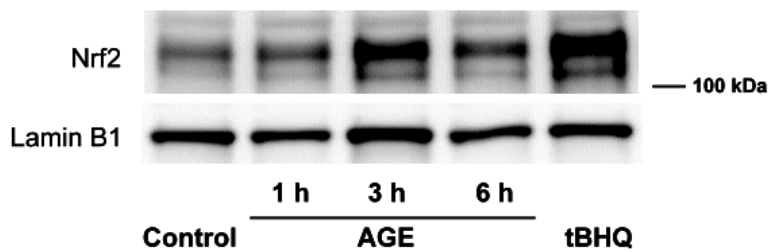

Figure 7. Nuclear translocation of Nrf2 by AGE. Nuclear extracts were prepared from SH-SY5Y cells treated with tBHQ $(50 \mu \mathrm{M})$ for $3.5 \mathrm{~h}$ or AGE $(4 \mathrm{mg} / \mathrm{ml})$ for 1,3 or $6 \mathrm{~h}$. The extracts $(10 \mu \mathrm{g})$ were subjected to Western blot analysis by using anti-Nrf2 and anti-lamin B1 antibodies.

lular antioxidant system via the Nrf2-ARE pathway, we next examined the effect of AGE pre-treatment on the cell death induced by 6-OHDA. SH-SY5Y cells were pre-incubated with AGE $(4 \mathrm{mg} / \mathrm{ml})$ for 6 or $24 \mathrm{~h}$, and then cells were washed and exposed to 6-OHDA (100 M) in the absence of AGE. As shown in Table 1, the extent of 6-OHDA-induced cell death was lower in cells pretreated with AGE than in those untreated control. It was noted, however, that the protective effect of pre-treatment was smaller compared to that found in the continuous presence of AGE (Figure 2), suggesting that the direct trapping of ROS by AGE was also important for its maximal antioxidant action.

\section{Discussion}

Using SH-SY5Y cells the protective effect of AGE was examined on the cytotoxicity induced by three test compounds, 6-OHDA, $\mathrm{MPP}^{+}$and $\mathrm{ACNU}$, that caused nerve cell death. Among three test compounds examined, the protective effect of AGE was only observed in the case of 6-OHDA that produced ROS (Figures 2 and 5). For the lower extent of cell damage induced by $100 \mu \mathrm{M}$ of 6-OHDA, a lower level of AGE $(2 \mathrm{mg} / \mathrm{ml})$ was enough to provide the significant protection of cell viability, while a higher level of AGE $(4 \mathrm{mg} / \mathrm{ml})$ was required to counteract the effect of the higher concentration of 6-OHDA $(150 \mu \mathrm{M})$. Previous studies showed that AGE possesses antioxidant activity [11] by scavenging ROS [11,36,37]. Our results shown in Figure 5 confirmed that AGE was capable of reducing the cellular ROS induced by 6OHDA.

AGE pre-treatment also protected the cell death induced by 6-OHDA (Table 1). We found this protection was accompanied by the activation of the Nrf2-ARE pathway (Figures 6 and 7). The activation mechanism of AGE is so far not clear, but several possibilities are conceivable [39]. It is known that oxidative stress causes the liberation of Nrf2 from Keap1 in the Nrf2-Keap1 complex, followed by the translocation of Nrf2 into nucleus and activation of ARE [24-28]. AGE produced a low but significant level of ROS as shown in Figure 5, and this effect may have served as a trigger. AGE contains a variety of compounds, some of which can stimulate the pro-

Table 1. The effect of AGE-pre-treatment on 6-OHDAinduced cytotoxicity. ${ }^{1}$

\begin{tabular}{|c|c|c|}
\hline \multirow{2}{*}{ Length of AGE pre-treatment } & \multicolumn{2}{|c|}{ Cell viability $\left(\%\right.$ of control $\left.^{2}\right)$} \\
\hline & $-\mathrm{AGE}$ & $+\mathrm{AGE}$ \\
\hline $6 \mathrm{~h}$ & $47.2 \pm 2.0$ & $55.1 \pm 3.5^{*}$ \\
\hline $24 \mathrm{~h}$ & $43.5 \pm 3.1$ & $57.1 \pm 1.9^{* *}$ \\
\hline
\end{tabular}

${ }^{1}$ SH-SY5Y cells were pre-treated without or with AGE $(4 \mathrm{mg} / \mathrm{ml})$ for 6 or $24 \mathrm{~h}$. After cells were washed twice with the fresh medium without AGE, cells were exposed to 6-OHDA $(100 \mu \mathrm{M})$ for $24 \mathrm{~h}$. Cell viability was assayed using MTT assay. The data are expressed as mean \pm S.D. $(n=4)$ relative to ${ }^{2}$ the control system without both 6-OHDA and AGE. ${ }^{*}$ and ${ }^{* *}$ denote a significant difference, $(p<0.05$ and $p<0.01$, respectively), relative to the corresponding value of the system without AGE as evaluated by $t$-test. 
duction of ROS. Another possibility is that AGE contains some compounds that can react with and modify the SH group of cysteine residues of Keap1 molecule. It was reported that compounds such as sulforaphane and curcumin are metabolized to the active compounds that react with Keap1 to liberate Nrf2. Nrf2 then translocates and accumulates in nucleus and activates the Nrf2-ARE pathway $[39,41,42]$. AGE contains sulfide compounds such as diallyl sulfide, diallyl disulfide, diallyltrisulfide, ajoene, S-allylcysteine (SAC) and S-allylmercaptocysteine (SAMC) [43] and these compounds can be a possible candidate that reacts with the SH group of cysteine residues. Recently, some of these compounds were shown to have the ability to induce the nuclear accumulation of Nrf2 and stimulate the production of antioxidant enzymes such as NQO1 and HO-1 [44-49]. The third possibility is that the activation mechanism of Nrf2-ARE pathway by AGE is mediated through some kinase systems [39]. In neuronal cells, the activation of phosphatidylinositol 3-kinase (PI3K)/Akt pathway is associated with the antioxidant system in cells [50,51]. Recently several compounds including carnosol and ginsenoside have been shown to induce the activation of the Nrf2ARE pathway through the PI3K-Nrf2 system [50-53] or other systems $[44,45,48]$.

Since AGE is known to contain a variety of sulfur compounds including SAC and SAMC [43], we examined the protective effect of those compounds against 6-OHDA $(100 \mu \mathrm{M})$-induced cytotoxicity in SH-SY5Y cells. As shown in Supplemental Figure 1, SAMC showed the protective effect at doses ranging from 5 to $20 \mu \mathrm{g} / \mathrm{ml}$. Since the concentration of SAMC in $4 \mathrm{mg} / \mathrm{ml}$ of AGE is estimated to be approximately $2.0 \mu \mathrm{g} / \mathrm{ml}$, it is possible that the protective effect of AGE may be partly due to SAMC in combination with some other substances in AGE. On the other hand, SAC showed no protective effect on the cell viability even at the concentration as high as $100 \mu \mathrm{g} / \mathrm{ml}$ (data not shown). It is reported that both SAC and SAMC scavenge hydroxyl radical $[11,54]$, but SAC is unable to capture superoxide anion radical [54]. On the other hand, we previously reported that SAMC possesses the ability to scavenge superoxide anion radical [12]. If the main species of cytotoxic ROS produced by 6-OHDA is superoxide anion radical, the above results can be attributable to the action of SAMC. Hara et al. showed that 6-OHDA-induced neurotoxicity is at least in part caused by superoxide [55], that is in line with our current view.

Garlic or its preparations have been reported to possess antioxidant activity [11,37,56-58]. In addition, antioxidant agents have been shown to modulate oxidative stress-induced changes in hypertension, atherosclerosis and diabetes $[59,60]$. Recently, Park et al. reported that the aged red garlic extract, another form of garlic extract preparation, reduced pulmonary inflammation through HO-1 induction [61]. Since some of those diseases are chronic, the long-term intake of antioxidant agents including garlic may be warranted for prevention and treatment of these diseases. However, it is not practical to use raw garlic because it has various side effects including anemia, weight loss and growth retardation $[3,62]$. AGE, on the other hand, can be tolerated for an extended period of intake without the side effect of raw garlic, and therefore could be a useful means of treating those diseases.

In conclusion, the present findings indicated that AGE protects cells from ROS-induced damage through both capturing ROS directly and stimulating antioxidant gene expression via the Nrf2-ARE pathway, and suggested that AGE may be useful for prevention and treatment of chronic diseases associated with ROS-induced cell injury.

\section{Acknowledgements}

We thank Dr. Takami Oka of Wakunaga Pharmaceutical Co., Ltd. for his helpful advise, encouragement and the critical reading of this manuscript. We thank Mr. Kei Hiramatsu, Dr. Naoaki Morihara, Dr. Kazuhiko Imamura and Dr. Yukihiro Kodera of Wakunaga Pharmaceutical Co., Ltd. for their help. We also thank Wakunaga Pharmaceutical Co., Ltd. for the supply of AGE, SAM and SAMC. This study was supported in part by Musashino Jyoshi-Gakuin Special Research Fund and by Wakunaga Research Fund.

\section{REFERENCES}

[1] J. G. Dausch and D. W. Nixon, "Garlic: A Review of Its Relationship to Malignant Disease," Preventive Medicine, Vol. 19, No. 3, 1990, pp. 346-361. doi:10.1016/0091-7435(90)90034-H

[2] H. Amagase, B. L. Petesch, H. Matsuura, S. Kasuga and Y. Itakura, "Intake of Garlic and Its Bioactive Components," The Journal of Nutrition, Vol. 131, No. 3S, 2001, pp. 955S-962S.

[3] S. Nakagawa, K. Masamoto, H. Sumiyoshi, K. Kunihiro and T. Fuwa, "Effect of Raw and Extracted-Aged Garlic Juice on Growth of Young Rats and Their Organs after Peroral Administration," The Journal of Toxicological Sciences, Vol. 5, No. 1, 1980, pp. 91-112. doi:10.2131/jts.5.91

[4] M. Ushijima, I. Sumioka, N. Kashimoto, K. Yokoyama, N. Uda, H. Matsuura, E. Kyo, A. Suzuki, S. Kasuga, Y. Itakura, B. L. Petesch and H. Amagase, "Effect of Garlic and Garlic Preparations on Physiological and Psychological Stress in Mice," Phytotherapy Research, Vol. 11, No. 3, 1997, pp. 226-230. 
doi:10.1002/(SICI)1099-1573(199705)11:3<226::AID-PT R85>3.0.CO;2-E

[5] N. Morihara, M. Ushijima, N. Kashimoto, I. Sumioka, T. Nishihama, M. Hayama and H. Takeda, "Aged Garlic Extract Ameliorates Physical Fatigue," Biological \& Pharmaceutical Bulletin, Vol. 29, No. 5, 2006, pp. 962-966. doi:10.1248/bpb.29.962

[6] E. Kyo, N. Uda, S. Kasuga and Y. Itakura, "Immunomodulatory Effects of Aged Garlic Extract," The Journal of Nutrition, Vol. 131, No. 3S, 2001, pp. 1075S-1079S.

[7] M. J. Budoff, N. Ahmadi, K. M. Gul, S. T. Liu, F. R. Flores, J. Tiano, J. Takasu, E. Miller and S. Tsimikas, "Aged Garlic Extract Supplemented with B Vitamins, Folic Acid and L-Arginine Retards the Progression of Subclinical Atherosclerosis: A Randomized Clinical Trial," Preventive Medicine, Vol. 49, No. 2-3, 2009, pp. 101107. doi:10.1016/j.ypmed.2009.06.018

[8] N. Morihara, N. Ide and N. Weiss, "Aged Garlic Extract Inhibits CD36 Expression in Human Macrophages via Modulation of the PPARgamma Pathway," Phytotherapy Research, Vol. 24, No. 4, 2010, pp. 602-608. doi:10.1002/ptr.3008

[9] N. Morihara, I. Sumioka, T. Moriguchi, N. Uda and E. Kyo, "Aged Garlic Extract Enhances Production of Nitric Oxide,” Life Sciences, Vo. 71, No. 5, 2002, pp. 509-517. doi:10.1016/S0024-3205(02)01706-X

[10] I. Sumioka, T. Matsura and K. Yamada, "Therapeutic Effect of S-Allylmercaptocysteine on AcetaminophenInduced Liver Injury in Mice," Europian Journal of Pharmacology, Vol. 433, No. 2-3, 2001, pp. 177-185. doi:10.1016/S0014-2999(01)01503-5

[11] J. Imai, N. Ide, S. Nagae, T. Moriguchi, H. Matsuura and Y. Itakura, "Antioxidant and Radical Scavenging Effects of Aged Garlic Extract and Its Constituents," Planta Medica, Vol. 60, No. 5, 1994, pp. 417-420. doi:10.1055/s-2006-959522

[12] K. Kohda, K. Itoh, H. Goda, K. Samejima, T. Fukuuchi, N. Morihara, K. Imamura, Y. Kodera and T. Oka, "Enhancing Effect of Aged Garlic Extract on Induction of Morphological Differentiation with Neurite Outgrowth in NGF-Treated PC12 Cells," Pharmacology \& Pharmacy, Vol. 3, No. 1, 2012, pp. 37-43. doi:10.4236/pp.2012.31006

[13] D. Anderson, "Antioxidant Defences against Reactive Oxygen Species Causing Genetic and Other Damage," Mutation Research, Vol. 350, No. 1, 1996, pp. 103-108. doi:10.1016/0027-5107(95)00096-8

[14] K. F. Gey, "The Antioxidant Hypothesis of Cardiovascular Disease: Epidemiology and Mechanisms," Biochemical Society Transactions, Vol. 18, No. 6, 1990, pp. 10411045. doi:10.1042/bst0181041

[15] D. Harman, "Role of Antioxidant Nutrients in Aging: Overview," AGE, Vol. 18, 1995, pp. 51-62. doi:10.1007/BF02432519

[16] V. M. Adhami, A. Malik, N. Zaman, S. Sarfaraz, I. A. Siddiqui, D. N. Syed, F. Afaq, F. S. Pasha, M. Saleem and H. Mukhtar, "Combined Inhibitory Effects of Green
Tea Polyphenols and Selective Cyclooxygenase-2 Inhibitors on the Growth of Human Prostate Cancer Cells both in Vitro and in Vivo," Clinical Cancer Research, Vol. 13, No. 5, 2007, pp. 1611-1619. doi:10.1158/1078-0432.CCR-06-2269

[17] I. Tahirovic, E. Sofic, A. Sapcanin, I. Gavrankapetanovic, L. Bach-Rojecky, M. Salkovic-Petrisic, Z. Lackovic, S. Hoyer and P. Riederer, "Brain Antioxidant Capacity in Rat Models of Betacytotoxic-Induced Experimental Sporadic Alzheimer's Disease and Diabetes Mellitus," Journal of Neural Transmission. Supplement, No. 72, 2007, pp. 235-240.

[18] H. Tsumoto, S. Kawahara, Y. Fujisawa, T. Suzuki, H. Nakagawa, K. Kohda and N. Miyata, "Syntheses of Water-Soluble [60]Fullerene Derivatives and Their Enhancing Effect on Neurite Outgrowth in NGF-Treated PC12 Cells," Bioorganic \& Medicinal Chemistry Letters, Vol. 20, No. 6, 2010, pp. 1948-1952. doi:10.1016/j.bmcl.2010.01.142

[19] T. Baati, F. Bourasset, N. Gharbi, L. Njim, M. Abderrabba, A. Kerkeni, H. Szwarc and F. Moussa, "The Prolongation of the Lifespan of Rats by Repeated Oral Administration of [60]Fullerene," Biomaterials, Vol. 33, No. 19, 2012, pp. 4936-4946. doi:10.1016/j.biomaterials.2012.03.036

[20] H. Hara, M. Ohta, K. Ohta, S. Kuno and T. Adachi, "Apomorphine Attenuates 6-Hydroxydopamine-Induced Apoptotic Cell Death in SH-SY5Y Cells," Redox Report, Vol. 8, No. 4, 2003, pp. 193-197. doi: $10.1179 / 135100003225002682$

[21] W. S. Choi, S. Y. Yoon, T. H. Oh, E. J. Choi, K. L. O'Malley and Y. J. Oh, "Two Distinct Mechanisms Are Involved in 6-Hydroxydopamine- and MPP+-Induced Dopaminergic Neuronal Cell Death: Role of Caspases, ROS, and JNK," Journal of Neuroscience Research, Vol. 57, No. 1, 1999, pp. 86-94 doi:10.1002/(SICI)1097-4547(19990701)57:1<86::AID-J NR9>3.0.CO;2-E

[22] R. von Coelln, S. Kugler, M. Bahr, M. Weller, J. Dichgans and J. B. Schulz, "Rescue from Death but Not from Functional Impairment: Caspase Inhibition Protects Dopaminergic Cells against 6-Hydroxydopamine-Induced Apoptosis but Not against the Loss of Their Terminals," Journal of Neurochemistry, Vol. 77, No. 1, 2001, pp. 263273. doi:10.1046/j.1471-4159.2001.t01-1-00236.x

[23] G. Walkinshaw and C. M. Waters, "Neurotoxin-Induced Cell Death in Neuronal PC12 Cells Is Mediated by Induction of Apoptosis," Neuroscience, Vol. 63, No. 4, 1994, pp. 975-987. doi:10.1016/0306-4522(94)90566-5

[24] R. Venugopal and A. K. Jaiswal, "Nrf1 and Nrf2 Positively and c-Fos and Fra1 Negatively Regulate the Human Antioxidant Response Element-Mediated Expression of NAD(P)H: Quinone Oxidoreductase1 Gene," Proceedings of the National Academy of Sciences of the United States of America, Vol. 93, No. 25, 1996, pp. 14960-14965. doi:10.1073/pnas.93.25.14960

[25] J. Alam, D. Stewart, C. Touchard, S. Boinapally, A. M. K. Choi and J. L. Cook, 'Nrf2, a Cap'n'Collar Transcription 
Factor, Regulates Induction of the Heme Oxygenase-1 Gene," The Journal of Biological Chemistry, Vol. 274, No. 37, 1999, pp. 26071-26078. doi:10.1074/jbc.274.37.26071

[26] H. Motohashi and M. Yamamoto, "Nrf2-Keap1 Defines a Physiologically Important Stress Response Mechanism," Trends in Molecular Medicine, Vol. 36, No. 11, 2004, pp. 549-557. doi:10.1016/i.molmed.2004.09.003

[27] A. K. Jaiswal, "Nrf2 Signaling in Coordinated Activation of Antioxidant Gene Expression," Free Radical Biology and Medicine, Vol. 36, No. 10, 2004, pp. 1199-1207. doi:10.1016/j.freeradbiomed.2004.02.074

[28] K. Itoh, N. Wakabayashi, Y. Katoh, T. Ishii, K. Igarashi, J. D. Engel and M. Yamamoto, "Keap1 Represses Nuclear Activation of Antioxidant Responsive Elements by Nrf2 through Binding to the Amino-Terminal Neh2 Domain," Genes \& Development, Vol. 13, No. 1, 1999, pp. 76-86. doi:10.1101/gad.13.1.76

[29] J. M. Lee, J. D. Moehlenkamp, J. M. Hanson and J. A. Johnson, "Nrf2-Dependent Activation of the Antioxidant Responsive Element by Tert-Butylhydroquinone Is Independent of Oxidative Stress in IMR-32 Human Neuroblastoma Cells," Biochemical Biophysical Research Communications, Vol. 280, No. 1, 2001, pp. 286-292. doi:10.1006/bbrc. 2000.4106

[30] T. Mosmann, "Rapid Colorimetric Assay for Cellular Growth and Survival: Application to Proliferation and Cytotoxicity Assays," Journal of Immunological Methods, Vol. 65, No. 1-2, 1983, pp. 55-63. doi:10.1016/0022-1759(83)90303-4

[31] A. S. Keston and R. Brandt, "The Fluorometric Analysis of Ultramicro Quantities of Hydrogen Peroxide," Analytical Biochemistry, Vol. 11, No. 1, 1965, pp. 1-5. doi:10.1016/0003-2697(65)90034-5

[32] H. Hara and T. Adachi, "Contribution of Hepatocyte Nuclear Factor-4 to Down-Regulation of CYP2D6 Gene Expression by Nitric Oxide," Molecular Pharmacology, Vol. 61, No. 1, 2002, pp. 194-200. doi:10.1124/mol.61.1.194

[33] M. M. Bradford, "A Rapid and Sensitive Method for the Quantitation of Microgram Quantities of Protein Utilizing the Principle of Protein-Dye Binding," Analytical Biochemistry, Vol. 72, No. 1-2, 1976, pp. 248-254. doi:10.1016/0003-2697(76)90527-3

[34] K. Kohda, Y. Noda, S. Aoyama, M. Umeda, T. Sumino, T. Kaiya, W. Maruyama and M. Naoi, "Cytotoxicity of 1-Amino-4-phenyl-1,2,3,6-tetrahydropyridine and 1-Amino-4-phenylpyridinium Ion, 1-Amino Analogues of MPTP and $\mathrm{MPP}^{+}$, to Clonal Pheochromocytoma PC12 Cells," Chemical Research in Toxicology, Vol. 11, No. 11, 1998, pp. 1249-1253. doi:10.1021/tx9800320

[35] K. Mineura, I. Izumi, K. Watanabe, M. Kowada, K, Kohda, K. Koyama, I. Terashima and M. Ikenaga, "Enhancing Effect of $O^{6}$-Alkylguanine Derivatives on Chloroethylnitrosourea Cytotoxicity toward Tumor Cells," International Journal of Cancer, Vol. 58, No. 5, 1994, pp. 706-712. doi:10.1002/ijc.2910580515

[36] N. Morihara, N. Ide, I. Sumioka and E. Kyo, "Aged Garlic Extract Inhibits Peroxynitrite-Induced Hemolysis,"
Redox Report, Vol. 10, No. 3, 2005, pp. 159-165. doi:10.1179/135100005X57364

[37] N. Morihara, M. Hayama and H. Fujii, "Aged Garlic Extract Scavenges Superoxide Radicals," Plant Hoods for Human Nutrition, Vol. 66, No. 1, 2011, pp. 17-21. doi:10.1007/s11130-011-0216-6

[38] R. Venugopal and A. K. Jaiswal, "Nrf2 and Nrf1 in Association with Jun Proteins Regulate Antioxidant Response Element-Mediated Expression and Coordinated Induction of Genes Encoding Detoxifying Enzyme," Oncogene, Vol. 17, No. 24, 1998, pp. 3145-3156.

[39] A. L. Eggler, K. A. Gay and A. D. Mesecar, "Molecular Mechanisms of Natural Products in Chemoprevention: Induction of Cytoprotective Enzymes by Nrf2," Molecular Nutrition \& Food Research, Vol. 52, Suppl. 1, 2008, pp. S84-S94.

[40] K. W. Kang, S. J. Lee, J. W. Park and S. J. Kim, "Phosphatidylinositol 3-Kinase Regulates Nuclear Translocation of NF-E2-Related Factor 2 through Actin Rearrangement in Response to Oxidative Stress," Molecular Pharmacology, Vol. 62, No. 5, 2002, pp. 1001-1010. doi:10.1124/mol.62.5.1001

[41] A. T. Dinkova-Kostova, W. D. Holtzclaw, R. N. Cole, K. Itoh, N. Wakabayashi, Y. Katoh, M. Yamamoto and P. Talalay, "Direct Evidence That Sulfhydryl Groups of Keap1 Are the Sensors Regulating Induction of Phase 2 Enzymes That Protect against Carcinogens and Oxidants," Proceedings of the National Academy of Sciences of the United States of America, Vol. 99, No. 18, 2002, pp. 11908-11913. doi:10.1073/pnas.172398899

[42] X. Gao, A. T. Dinkova-Kostova and P. Talalay, "Powerful and Prolonged Protection of Human Retinal Pigment Epithelial Cells, Keratinocytes, and Mouse Leukemia Cells against Oxidative Damage: The Indirect Antioxidant Effects of Sulforaphane," Proceedings of the $\mathrm{Na}$ tional Academy of Sciences of the United States of America, Vol. 98, No. 26, 2001, pp. 15221-15226. doi:10.1073/pnas.261572998

[43] Y. Kodera, H. Matsuura, H. Sumiyoshi and S. Sumi, "Garlic Chemistry: Chemical and Biological Properties of Sulfur-Containing Compounds Derived from Garlic," In: F. Shahadi, C. T. Ho, S. Watanabe and T. Osawa, Eds., ACS Symposium Series 851. Food Factors in Health Promotion and Disease Prevention, Oxford University Press, Oxford, 2003, pp. 346-357.

[44] C. Y. Ho, Y. T. Cheng, C. F. Chau and G. C. Yen, "Effect of Diallyl Sulfide on in Vitro and in Vivo Nrf2-Mediated Pulmonic Antioxidant Enzyme Expression via Activation ERK/p38 Signaling Pathway," Journal of Agricultural and Food Chemistry, Vol. 60, No. 1, 2012, pp. 100-107. doi:10.1021/jf203800d

[45] H. Y. Kay, J. Won Yang, T. H. Kim, D. Y. Lee, B. Kang, J. H. Ryu, R. Jeon and S. J. Kim, "Ajoene, a Stable Garlic By-Product, Has an Antioxidant Effect through Nrf2Mediated Glutamate-Cysteine Ligase Induction in HepG2 Cells and Primary Hepatocytes," The Journal of Nutrition, Vol. 140, No. 7, 2010, pp. 1211-1219. doi:10.3945/jn.110.121277

[46] S. Kalayarasan, N. Sriram, A. Sureshkumar and G. Sud- 
handiran, "Chromium (VI)-Induced Oxidative Stress and Apoptosis Is Reduced by Garlic and Its Derivative S-Allylcysteine through the Activation of Nrf2 in the Hepatocytes of Wistar Rats," Journal of Applied Toxicology, Vol. 28, No. 7, 2008, pp. 908-919. doi:10.1002/jat.1355

[47] C. D. Fisher, L. M. Augustine, J. M. Maher, D. M. Nelson, A. L. Slitt, C. D. Klaassen, L. D. Lehman-McKeeman and N. J. Cherrington, "Induction of Drug-Metabolizing Enzymes by Garlic and Allyl Sulfide Compounds via Activation of Constitutive Androstane Receptor and Nuclear Factor E2-Related Factor 2," Drug Metabolism \& Disposition, Vol. 35, No. 6, 2007, pp. 9951000. doi:10.1124/dmd.106.014340

[48] C. Chen, D. Pung, V. Leong, V. Hebbar, G. Shen, S. Nair, W. Li and A. N. Kong, "Induction of Detoxifying Enzymes by Garlic Organosulfur Compounds through Transcription Factor Nrf2: Effect of Chemical Structure and Stress Signals," Free Radical Biology \& Medicine, Vol. 37, No. 10, 2004, pp. 1578-1590. doi:10.1016/j.freeradbiomed.2004.07.021

[49] A. O. Lawal and E. M. Ellis, "The Chemopreventive Effects of Aged Garlic Extract against Cadmium-Induced Toxicity," Environmental Toxicology and Pharmacology, Vol. 32, No. 2, 2011, pp. 266-274. doi:10.1016/j.etap.2011.05.012

[50] D. Martin, A. I. Rojo, M. Salinas, R. Diaz, G. Gallardo, J. Alam, C. Ruiz de Galarreta and A. Cuadrado, "Regulation of Heme Oxygenase-1 Expression through the Phosphatidylinositol 3-Kinase/Akt Pathway and the Nrf2 Transcription Factor in Response to the Antioxidant Phytochemical Carnosol," The Journal of Biological Chemistry, Vol. 279, No. 10, 2004, pp. 8919-8929. doi:10.1074/jbc.M309660200

[51] M. Salazar, A. I. Rojo, D. Velasco, R. Maria de Sagarra and A. Cuadrado, "Grycogen Synthase Kinase-3b Inhibits the Xenobiotic and Antioxidant Cell Response by Direct Phosphorylation and Nuclear Exclusion of the Transcription Factor Nrf2," The Journal of Biological Chemistry, Vol. 281, No. 21, 2006, pp. 14841-14851. doi:10.1074/jbc.M513737200

[52] Y. P. Hwang and H. G. Jeong, "Ginsenoside Rb1 Protects against 6-Hydroxydopamine-Induced Oxidative Stress by Increasing Heme Oxygenase-1 Expression through an Estrogen Receptor-Related PI3K/Akt/Nrf2-Dependent Pathway in Human Dopaminergic Cells," Toxicology and Applied Pharmacology, Vol. 242, No. 1, 2010, pp. 18-28. doi:10.1016/j.taap.2009.09.009

[53] K. Nakaso, C. Nakamura, H. Sato, K. Imamura, T. Takeshima and K. Nakashima, "Novel Cytoprotective Mechanism of Anti-Parkinsonian Drug Deprenyl: PI3K and
Nrf2-Derived Induction of Antioxidative Proteins," Biochemical Biophysical Research Communications, Vol. 339, No. 3, 2006, pp. 915-922. doi:10.1016/j.bbrc.2005.11.095

[54] L. Y. Chung, "The Antioxidant Properties of Garlic Compounds: Allyl Cysteine, Alliin, Allicin and Allyl Disulfide," Journal of Medicinal Food, Vol. 9, No. 2, 2006, pp. 205-213. doi:10.1089/jmf.2006.9.205

[55] H. Hara, H. Hiramatsu and T. Adachi, "Pyrroloquinoline Is a Potent Neuroprotective Nutrient against 6-Hydroxydopamine-Induced Neurotoxicity," Neurochemical Research, Vol. 32, No. 3, 2007, pp. 489-495. doi:10.1007/s11064-006-9257-X

[56] S. K. Banerjee, P. K. Mukherjee and S. K. Maulik, "Garlic as an Antioxidant: The Good, the Bad and the Ugly," Phytotherapy Research, Vol. 17, No. 2, 2003, pp. 97-106. doi:10.1002/ptr.1281

[57] H. Drobiova, M. Thomson, K. Al-Qattan, R. PeltonenShalaby, Z. Al-Amin and M. Ali, "Garlic Increases Antioxidant Levels in Diabetic and Hypertensive Rats Determined by a Modified Peroxidase Method," EvidenceBased Complementary Alternative Medicine, Vol. 2011, 2011, Article ID 703049. doi:10.1093/ecam/nep011

[58] L. H. Park, Y. K. Park and E. Park, "Antioxidative and Antigenotoxic Effects of Garlic (Allium sativum L.) Prepared by Different Processing Methods," Plant Foods for Human Nutrition, Vol. 64, No. 4, 2009, pp. 244-249. doi:10.1007/s11130-009-0132-1

[59] A. Ceriello, "New Insights on Oxidative Stress and Diabetic Complications May Lead to a 'Causal' Antioxidant Therapy,” Diabetes Care, Vol. 26, No. 5, 2003, pp. 15891596. doi:10.2337/diacare.26.5.1589

[60] S. Vasdev, V. D. Gill and P. K. Singal, "Modulation of Oxidative Stress-Induced Changes in Hypertension and Atherosclerosis by Antioxidants," Experimental \& Clinical Cardiology, Vol. 11, No. 3, 2006, pp. 206-216.

[61] H. J. Park, B. T. Jeon, H. C. Kim, G. S. Roh, J. H. Shin, N. J. Sung, J. Han and D. Kang, "Aged Red Garlic Extract Reduces Lipopolysaccharide-Induced Nitric Oxide Production in RAW 264.7 Macrophages and Acute Pulmonary Inflammation through Haeme Oxygenase-1 Induction," Acta Physiologica, Vol. 205, No. 1, 2012, pp. 61-70. doi:10.1111/j.1748-1716.2012.02425.x

[62] H. Sumiyoshi, A. Kanezawa, K. Masamoto, H. Harada, S. Nakagami, A. Yokota, M. Nishikawa and S. Nakagawa, "Chronic Toxicity Test of Garlic Extract in Rats," The Journal of Toxicological Sciences, Vol. 9, No. 1, 1984, pp. 61-75. doi:10.2131/jts.9.61 


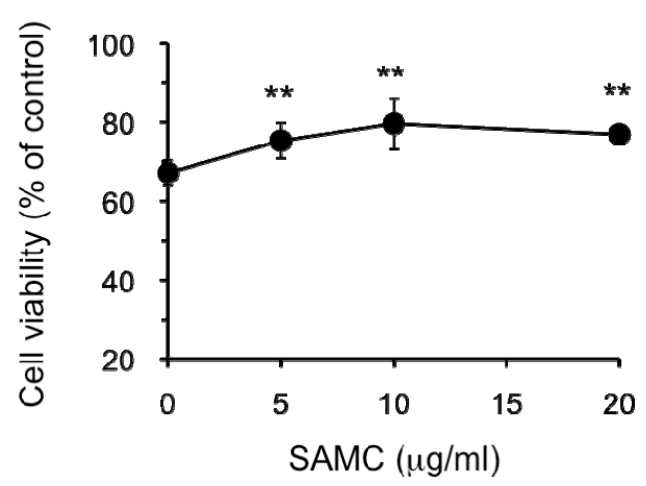

Supplemental Figure 1. Effect of SAMC on 6-OHDA-induced cytotoxicity. The experimental procedures are the same as described in the Figure 2 legend except that only $100 \mu \mathrm{M}$ of 6-OHDA was used. The data are expressed as mean \pm S.D. $\left(n=5\right.$ - 6). ${ }^{* *}$ Denotes a significant difference compared with the value of cell viability without SAMC $(p<0.01)$ as evaluated by $t$-test. 